\title{
Letters
}

Website: www.bmj.com

Email: letters@bmj.com

\section{Data support extended use of levonorgestrel intrauterine systems}

EDITOR-The levonorgestrel intrauterine system (Mirena), a useful addition to contraceptive choice, is now approaching its third anniversary.

In the United Kingdom the product licence for the levonorgestrel intrauterine system permits its use for three years. In all other countries where the system is marketed, however, its use is approved for five years. There is good evidence to support this longer duration, ${ }^{1}$ and indeed the system seems to remain effective for as long as seven years. ${ }^{2}$ We understand that Schering Healthcare has applied for a two year extension to its current licence, backed by their new data that relates to the new polymer that has been used since 1990 .

Many clinicians have asked us if they should conform strictly to the current product licence and replace each intrauterine system on the third anniversary of its insertion. We would strongly advise delaying reinsertion in this time, at least until the expected statement from the Medicines Control Agency.

It is well known that the process of insertion of all intrauterine contraceptives causes problems (short term inconvenience and discomfort followed by new bleeding and pain or expulsion) and also real risks, ${ }^{3}{ }^{4}$ notably

\footnotetext{
Advice to authors

We prefer to receive all responses electronically, sent either directly to our website or to the editorial office as email or on a disk. Processing your letter will be delayed unless it arrives in an electronic form.

We are now posting all direct submissions to our website within 72 hours of receipt and our intention is to post all other electronic submissions there as well. All responses will be eligible for publication in the paper journal.

Responses should be under 400 words and relate to articles published in the preceding month. They should include $\leqslant 5$ references, in the Vancouver style, including one to the BMJ article to which they relate. We welcome illustrations.

Please supply each author's current appointment and full address, and a phone or fax number or email address for the corresponding author. We ask authors to declare any conflicts of interest.

Letters will be edited and may be shortened.

www.bmj.com

letters@bmj.com
} These would be unacceptable if it emerges that reinsertions were not necessary.

Users of the levonorgestrel intrauterine system can be reassured that good data are available to support its use for five years. From 15 May, and until any statement concerning a change in the licence, continuation beyond three years is legitimate, at the woman's choice, provided the established criteria for use by named patients are observed-that is, explaining that this is unlicensed use of a licensed product; highlighting the risks and benefits of the proposed non-intervention; obtaining and recording the woman's verbal consent in her case notes; and keeping a separate record of the woman's name and the nature of the unlicensed use. ${ }^{5}$

Diana Mansour Medical advisor

Margaret Pyke Memorial Trust, London W1P 1LB

John Guillebaud Medical director

Margaret Pyke Family Planning Centre, London W1P 1LB

Conflict of interest: The Margaret Pyke Memorial Trust is in receipt of research funds from Leiras and from Schering for three ongoing studies of Mirena, and has received research or educational grants from the previous franchisee Pharmacia and Upjohn. DM and JG received ad hoc consultancy and lecture fees and associated expenses from these and other unrelated pharmaceutical companies.

1 Irving S, El Mahgoub S, McCarthy T, Mishell Jr DR Shoupe D, Alvarez F, et al. Long term contraception with the Levonorgestrel $20 \mathrm{mcg} / \mathrm{day}$ (LNg 20) and the Coppe T $380 \mathrm{Ag}$ intrauterine devices: a five year randomised study. Contraception 1990;42:361-78.

2 Sivin I, Stern J, Coutinho E, Mattos C, El Mahgoub S, Diaz $\mathrm{S}$, et al. Prolonged intrauterine contraception: a seven yea randomised study of the levonorgestrel $20 \mathrm{mcg} /$ day (LN 20) and the copper T 380 Ag IUDs. Contraception 1991; 44:473-80.

3 World Health Organisation. Mechanism of action, safety and efficacy of intrauterine devices. Report of the Who Scientific Group: Geneva: WHO, 1987. (WHO technical report series 753).

4 Guillebaud J. Contraception. In: McPherson A, Waller D, eds. Women's health Oxford: Oxford University Press, 1997; $182-9$

5 Guillebaud J. Use of licensed products in an unlicensed way. Contraception today. 3rd ed. London: Martin Dunitz 1997:94-5

\section{Are sex and death related?}

\section{Study failed to adjust for an importan} confounder

EDIToR-Davey Smith et al report a significant inverse relation between frequency of orgasm and mortality due to all causes and coronary heart disease in men; however, a failure to adjust for the energy expended perforation and upper genital tract infection. during sexual activity may be a weakness of their work. ${ }^{1}$ The intensity level of sexual activity is equivalent to that of leisurely walking or strolling, ${ }^{2}$ and an increasing level of energy output, even when amassed during walking, is independently associated with a decreased risk of all cause mortality. ${ }^{3}$ This failure to adjust for the energy cost of sexual activity may be amplified if, as seems plausible, the more sexually active individuals have a stronger disposition to physical activity per se than their less virile counterparts.

David Batty Researcher

University of Bristol, Exercise and Health Research Unit, Woodland House, Bristol BS8 2LU

1 Davey Smith G, Frankel S, Yarnell J. Sex and death: are they related? Findings from the Caerphilly cohort study. BMJ 1997;315:1641-5. (20-27 December.)

2 Ainsworth BE, Haskell WL, Leon AR, Jacobs DR, Montoye HJ, Sallis JF, et al. Compendium of physical activities: classification of energy costs of human physical activities. Med Sci Sports Exerc 1993;25:71-80.

3 Hakim AA, Petrovitch H, Burchfiel CM, Ross GW, Rodriguez BL, White LR, et al. Effects of walking on mortality among nonsmoking retired men. $N$ Engl J Med tality among 1998 ; 34 .

Study did not treat sexual behaviour with the importance it deserves

EDITOR-The article by Davey Smith et al on sexual behaviour and mortality was a disappointment. ${ }^{1}$ The topic is important, and the results should at least be correct. I was surprised by the simplistic design, the mechanical interpretation of the results, and the selective use of references-even from the Holy Bible. ${ }^{2}$ Although long term follow up studies have to cope with shifts in medical thinking by the time of publication, this should have been addressed in the discussion. Even in the late seventies, during the time of the study's design, psychological understanding of human sexuality was rather more complex than the authors imply. Firstly, not even minimal information on partners or relationships was included. Indeed, marital status was not mentioned and they gave no reason for this, despite numerous published studies on the relation between mortality and marital status before and since the seventies. ${ }^{34}$ It is likely that those men who had regular sexual activity in late middle age were either married or in long term relationships. The greater longevity of married compared with unmarried people has been shown repeatedly ${ }^{5}$ and this might be an important confounding factor. Secondly, it was naive to use the term sexual intercourse and orgasm interchangeably. If the authors were mainly interested in the health effect of orgasm, as a purely biological phenomenon, surely masturbation should not have been ignored. Thirdly, 
it is unlikely that sexual behaviour is static. As Hotopf and Wessely pointed out in their comment, sexual activity is influenced by age, health factors, and psychopathology. ${ }^{1}$ To these might be added changes in relationships, loss of spouse etc, which were not addressed, implying that the authors believe one self report measure is adequate to describe a person's sexual activity during an entire lifetime, or at least from the age of 45 to death. Given these shortcomings, the authors should have been more cautious in their conclusions. The only message from this study is that the topic needs further (and more sophisticated) investigation. Inventing new health promotion slogans with numerical imperatives would be premature and should certainly be withheld.

Agnes Ayton Specialist registrar in child and adolescent psychiatry

Lime Trees Child, Adolescent and Family Unit, York YO3 ORE

1 Davey Smith G, Frankel S, Yarnell J. Sex and death: are hey related? Findings from the Caerphilly cohort study BMJ 1997;315:1641-5. [With commentary by M Hotop and S Wessely.] (20-27 December.

2 Holy Bible. I Corinthians vii, 2-5.

3 Berkson J. Mortality and marital status: reflection on the derivation of etiology from statistics. Am J Public Health 1962;52:1318-29.

4 Goodwin JS, Hunt W, Key R, Samet JM. The effect of marireatment and survival of cancer patients JAMA 1987.258.3125-30.

5 Chand V V Szlo M, Goldber Tonascia J The impact of Chandra V, Szklo M, Goldberg R, Tonascia J. The impact of population based study. Am J Epidemiol 1983;117:320-5.

\section{Author's reply}

EDITOR-Our report on the association between sexual behaviour and mortality was intended to illustrate the findings that associational epidemiological studies can produce. ${ }^{1}$ This information adds to earlier publications on the subject, ${ }^{2}$ which we did make clear in the discussion. The findings have interest beyond this, however, and we would welcome further investigations. We agree with Batty that attention should be paid to physical activity, but conceptual clarity needs to be maintained when this is done. Batty states that we failed to adjust for physical activity, which he considers an important confounder. It is possible that men engaging in lots of sexual activity also participate in other forms of physical activity. Adjusting for energy expended during sexual activity, as suggested by Batty, would not be adjusting for confounding as the physical activity involved in sexual encounters could be the protective factor and, therefore, an integral part of the exposure. Investigation of this issue would be complex. Although Batty explains that the exertion of sexual activity is equivalent to that of leisurely walking or strolling, this would be different for adventurous couplings.

Our article was intended to fit in with the festive cheer of the $B M J^{3}{ }^{4}$ and to provide an introduction to associational findings in epidemiological studies. Ayton has missed both these points. The majority of our men were married and the results were identical if we restricted the analysis to married men. Our reference to health education was intended to be ironic, not least because the benefits exceeded those anticipated with most established health promotion programmes. Some readers obviously missed this mild mischief. In future, to spare disappointment at the end of the year perhaps Ayton should avoid the Christmas BMJ.

George Davey Smith Professor of clinical

epidemiology

Department of Social Medicine, University of Bristol, Bristol BS 2PR

1 Davey Smith G, Frankel S, Yarnell J. Sex and death: are hey related? Findings from the Caerphilly cohort study. BMJ 1997;315:1641-5. (20-27 December.)

2 Davey Smith G, Phillips AN, Neaton JD. Smoking as "independent" risk factor for suicide: illustration of an artefact from observational epidemiology? Lancet 1992;340:709-

Cleare AJ, Wessely SC. Just what the doctor ordered-more alcohol and sex. BMJ 1997;315:1637-8.

White IR, McKee M. Festive cheer for all? BMJ 1997;315: $1638-9$

\section{Cancer in the offspring of radiation workers}

\section{Connection between leukaemia and radiation needs to be considered}

EDIToR-The results of the study of Draper et al showing an association between worker status of parents and leukaemia in children are unlikely to be attributable to chance. Some exposure to a causative agent, either at the workplace of male radiation workers or in the communities to which they belong, must increase the risk of childhood leukaemia.

Draper et al suggest an oncogenic infectious agent that results from high rates of population mixing as the cause of increased leukaemia risk. Their evidence is based on three factors: an association of population mixing with childhood leukaemia; population mixing in the vicinity of certain nuclear sites; and worker migration between sites. These factors do not explain the excess risk of $80 \%$. A review of all the studies published at that time of childhood leukaemia in areas with high population mixing ${ }^{2}$ gave $50 \%$ as best estimate of increased risk, with only one having an estimate as high as $80 \%$.

The effects of population mixing, however, may be diluted in these workers for several reasons. Firstly, only a proportion will have been employed at establishments such as Sellafield. Secondly, the time windows of documented excess mixing near these plants are mostly short relative to the 34 years of this study. Thirdly, radiation worker status of the father before conception of the child is, here, an inaccurate measure of the relevant exposure (which presumably occurs after conception). Nevertheless, given the accumulating evidence that links patterns of exposure to infectious agents with childhood leukaemia, ${ }^{2}{ }^{3}$ an infectious origin for this excess should be considered.

So, I suggest, should a connection with radiation. Maybe an additional factor that applies to communities of radiation workers has the same effect as population mixingthat is, to favour microepidemics of the putative agent. The possible relevance of immunotoxic properties of ionising radiation in individual people has been proposed. ${ }^{4}$ The community effect on herd immunity can be much larger than the sum of small individual parts ${ }^{5}$ and could apply here. Immunosuppression of a human population would increase the risk of microepidemics by increasing the probability of infection after a single contact. In addition, for agents that establish latency it would increase the number of infectious people. Mild immunosuppression of the population may be another mechanism in communities that increases the risk of childhood leukaemia.

Case and control fathers ${ }^{1}$ should now be linked to National Registry of Radiation Workers records to determine radiation worker status after conception. Also linked, if possible, should be examination of contact between the fathers (employment at the same site at the same time), especially at critical periods such as gestation, the first year of life, and the year preceding diagnosis.

Freda Alexander Reader in cancer epidemiology University of Edinburgh, Department of Public Health Sciences, Edinburgh EH8 9AG

1 Draper GJ, Little MP, Sorahan T, Kinlen LJ, Bunch KJ, Conquest AJ, et al. Cancer in the offspring of radiation workers: a record linkage study. BMJ 1997;315;1181-9. (8 November.)

2 Kinlen LJ. Epidemiological evidence for an infective basi in childhood leukaemia. Br J Cancer 1995;71:1-5.

3 Greaves MF. Aetiology of acute leukaemia. Lancet 1997; 349:344-9.

4 Alexander FE. Viruses, clusters and clustering of childhood leukaemia: a new perspective? Eur J Cancer 1993;29:1424-43.

5 Starr JM, Rogers TR, Impallomeni M. Hospital-acquired Clostridium difficile diarrhoea and herd immunity. Lancet 1997:349:426-8.

\section{Exposure to internal radioisotopes may be responsible}

EDITOR-Draper et al find a 1.8-fold excess relative risk for leukaemia in children of male radiation workers and a fivefold relative risk in children of female workers. Since the highest risk does not follow the highest dose they conclude that exposure to radiation is not the cause of the leukaemia and that the Gardner hypothesis is refuted. This conclusion is unwarranted because exposure to internal radioisiotopes may be responsible.

Gardner was well aware that the external irradiation studies were at odds with his findings and wrote: "The interpretation [of our findings] in terms of a related causal mechanism is not known ... the examination of radionuclides and other occupational exposures is under way."'

Roman et al studied children of radiation workers in west Berkshire and drew different conclusions when they found a 2.2-fold excess risk of leukaemia:"The possibility that the effects could be due to internal contamination by radioactive substances ... should be explored."3

This was done by Rooney et al for risk of prostate cancer in nuclear workers. ${ }^{4}$ The excess risk had not followed a simplistic dose-response relation with external film badge doses, and the researchers could have concluded, like Draper et al, that ionising radiation was not the cause of cancer. Instead, they looked at internal contamina- 
tion and found significant evidence for enhancement of hazard as a result of internal exposure to a number of isotopesfor example, a relative risk of 14.2 for tritium. This suggests an error of more than 500 times in the current risk of prostate cancer based on Hiroshima. ${ }^{5}$ It is unsafe to assume that the excess risk of leukaemia is any different from the risk of prostate cancer without investigating this further.

In fact, Draper et al's study found an increased relative risk of 2.5 times for radiation workers who had been monitored for internal exposure, compared with 1.6 for those who had not been monitored. If internal radiation is the cause, then the true relative risks are far higher since the controls used by Draper et al were from local populations whose risk of internal contamination is higher than that of the general population.

Finally, Draper et al assert that although the increased risks exist they are small in absolute terms: the risk of 6.5 per 10000 (an error, presumably they mean per 100000 ) increases by 5.4 to 11.9 . This means that many children have died because their parents worked in the nuclear industry. No one should be comforted by how low the absolute numbers were.

Cris Busby Researcher

Molly Scott Cato Researcher

Green Audit, Aberystwyth SY23 1PU

1 Draper GJ, Little MP, Sorahan T, Kinlen LJ, Bunch KJ, Conquest AJ, et al Cancer in the offspring of radiation workers: a record linkage study BMJ 1997-315:1181-8. (8 November.)

2 Gardner MJ, Leukemia in children and paternal radiation exposure at the Sellafield nuclear site. I Natl Cancer Inst 1992;No 12:133-5. (Monograph.)

3 Roman E, Watson A, Beral V, Buckle S, Bull D, Baker K, et al. Case-control study of leukaemia and non-Hodgkin's al. Case-control study of leukaemia and non-Hodgkin's
lymphoma among children aged $0-4$ years living in west Berkshire annd north Hampshire health districts. BMJ Berkshire annd

1993;306:615-21.
Rooney C, Beral V, Moconochie N, Fraser P, Davies G

4 Rooney C, Beral V, Moconochie N, Fraser P, Davies G.
Case-control study of prostatic cancer in employees of the United Kingdom Atomic Energy Authority. BMJ 1993 307:1391-7.

5 Busby C. Increase in cancer in Wales unexplained, $B M$ J 1993;308:268

Combination of antibiotics and non-fatal infections may be responsible for higher number of deaths from leukaemia

EdITOR-Draper et $\mathrm{al}^{1}$ say that the most likely explanation for the excess of childhood leukaemia at Seascale seems to be infection promoted by population mixing, and they refer their readers to the Kinlen hypothesis. ${ }^{2}$ According to this hypothesis, leukaemia is a rare response to a widespread virus infection that only needs a large influx of people into a previously isolated place to produce an epidemic.

The existence of such viral epidemics is not in dispute. According to the Oxford survey of childhood cancers, however, children who die from leukaemia before they reach the age of 16 are abnormally sensitive to infection throughout their lifespan, ${ }^{3}$ and, in relation to leukaemia, pneumonia and other serious infections may be either competing causes of death ${ }^{4}$ or promoters of the neoplastic process. ${ }^{5}$

According to the survey, viral epidemics caused by population mixing might reduce the frequency of leukaemia by adding to the number of children who die before they show any signs of malignant disease. Nowadays, however, antibiotics save lives while non-fatal infections are known to promote cancer. As a result of this combination of factors, epidemics would probably have the opposite effect. The second alternative would not rule out a viral origin for leukaemia, but it offers a much simpler explanation of the Seascale cluster than the one advanced by Kinlen.

Alice Stewart Emeritus fellow

Leverhulme Trust, University of Birmingham,

Department of Public Health and Epidemiology, Birmingham B15 2TT

1 Draper GJ, Little MP, Sorahan T, Kinlen LJ, Bunch KJ, Conquest AJ, et al. Cancer in the offspring of radiatio workers: a record linkage study. BMJ 1997;315:1181-8. (8 November.)

Kinlen LJ. Evidence of an infectious cause of childhood leukaemia. Lancet 1988;ii;1323-7.

Stewart AM, Kneale GW. The immune system and cancer of foetal origin. Cancer Immunol Immunother 1982;14:110-6. 4 Kneale GW. Excess sensitivity of pre-leukaemics to pneumonia A model situation for studying the interaction of an infectious disease with cancer. Br J Prev Soc Med 1971;25:152-9.

5 Kneale GW, Stewart AM. Childhood cancers in the UK and their relations to background radiation. Radiation and Health 1987;16:203-20.

\section{Authors' reply}

EDITOR-Alexander draws attention to the fact that the excess of childhood leukaemia in our study is slightly higher than in most population mixing studies.

A point that deserves to be considered is the difference in design. Previous studies have covered total populations of certain areas, whereas ours concerned the industry in which the mixing was concentrated. It is therefore relevant that a marked excess of leukaemia among the children of men in another (the construction) industry has recently been reported in areas of marked rural population mixing, and it is higher than that in radiation workers. ${ }^{1}$ We are not aware of any evidence to suggest that Alexander's immunotoxic hypothesis is relevant to our findings. We agree with the suggestion about examining the links between cases of childhood cancer and radiation workers with exposures after conception; in fact, this has already been under discussion.

Busby and Cato misquote us. Firstly, we did not say that the Gardner hypothesis is refuted, merely that our results do not support it. Secondly, they have changed the tenor of our comment about risks. The issue here is, however, that it is important to present the absolute risks-neither exaggerating the results nor downplaying themand to avoid the misunderstandings that can occur when only relative risks are quoted for rare diseases. (The denominators for the absolute risks that we quoted are correct.) The possibility that Gardner's results were due to internally deposited radionuclides was considered in detail in the studies by the Health and Safety Executive that we quoted, but no support was found. These and other findings in relation to internally deposited radionuclides are discussed in our paper and in the full report referred to there.
We agree with Stewart that all plausible mechanisms should be considered to explain how any infective agent might influence the incidence of childhood malignancy.

G J Draper Director

Childhood Cancer Research Group, University of Oxford, Oxford OX2 6HJ

M P Little Principal scientific officer

National Radiological Protection Board, Chilton, Didcot OX11 0RQ

T Sorahan Reader in occupational epidemiology Institute of Occupational Health, University of Birmingham, Birmingham B15 2TT

L J Kinlen Director

Cancer Research Campaign, Cancer Epidemiology Research Group, Department of Public Health, Radcliffe Infirmary, University of Oxford, Oxford OX2 6 $\mathrm{HE}$

1 Kinlen LJ. High-contact paternal occupations, infection and childhood leukaemia: five studies of unusual population-mixing of adults. Br J Cancer 1997;76;1539-45.

\section{Cognitive impairment and survival in very elderly people}

Mini-mental state examination may not test cognitive function adequately

EDITOR-Gussekloo et al hypothesised that mild cognitive impairment as determined by the Dutch version of the mini-mental state examination discriminates subjects with a higher risk of mortality. ${ }^{1}$

We have concerns about the validity of using the mini-mental state examination as an adequate test of cognitive function. We have doubts about the reproducibility of test scores if the test is administered by different physicians. In clinical practice the minimental state examination is well recognised as being a useful guide rather than an absolute measure of cognitive function; it is a subjective test with variable results.

In particular, we think that defining the scores for mild cognitive impairment and normal cognitive function so close together, at 24-27 and 28-30 respectively, is a potential source of bias. A subject could fall into either category, depending on several variables affecting alertness, such as time of day, timing of drug treatment, stress, and discomfort.

The authors conclude that this test "seems to be useful as a screening instrument for mild cognitive impairment, and its scores may act as an important predictor of survival in very elderly people." ${ }^{1}$ Although this conclusion may be valid, we question the usefulness of such a prognostic indicator in clinical practice.

Pete Forster Fourth year medical student Emma Heckford Fourth year medical student Claire Huckler Fourth year medical student Nicole Keong Fourth year medical student Ahmed Al-Khabaz Fourth year medical student Department of Epidemiology and Public Health, School of Health Sciences, Medical School, University of Newcastle, Newcastle upon Tyne NE2 4HH

1 Gussekloo J, Westendorp RGJ, Remarque EJ, Lagaay AM, Hereen TJ, Knook DL. Impact of mild cognitive impairment on survival in very elderly people: cohort study. BMJ 1997;315:1053-4. (25 October.) 


\section{Decreased survival with cognitive impairment seems not to be related to comorbidity}

Editor-Gussekloo et al showed an increased mortality with increasing cognitive impairment in a population of very old subjects. ${ }^{1}$ Lower cognitive status in elderly people may also be due to chronic disease, and the risk of death might be entirely due to concurrent chronic diseases rather than to dementia. We investigated the effect of the number of diseases and their severity on mental state and survival in elderly patients.

We obtained data from the evaluation of 650 consecutive elderly patients on admission to a geriatric evaluation and rehabilitation unit over a period of 14 months. A standard protocol was used to assess demographic factors, mental and functional state, and somatic health. Somatic health was evaluated as the presence of 15 of the most common diseases in elderly patients in hospital and their severity. Severity was evaluated by Greenfield's individual disease severity index, in which each condition was graded from 0 (no disease) to 4 (greatest severity of disease). ${ }^{2}$ We excluded patients with terminal or wasting disease (renal or liver failure, malignant neoplasm, diabetes, or chronic inflammatory diseases).

Our population (mean age 79.2 (SD 7.4) years; 456 women $(70.2 \%)$ ) had moderate functional impairment (mean of 2.8 (2.0) functions $\operatorname{lost}^{3}$ ), mild depression (mean general depression score $\left.13.0(6.3)^{4}\right)$, and many diseases (mean 5.1 (2.7)). Overall, 113 patients died within 12 months after discharge (annual death rate 17.4\%).

Like Gussekloo et al, we identified four subgroups with decreasing cognitive status by using the mini-mental state examination. The table shows the crude risk of death in Cox's proportional hazard survival analysis. The severity of heart disease of ischaemic or organic origin, heart disease of other origin, respiratory disease, anaemia, malignancy, and renal disease was independently associated with mortality; disability and serum albumin concentration were also associated with greater mortality (data not shown). The table also shows that the association between cognitive impairment and mortality held after all confounders associated with mortality in the bivariate Cox's model were controlled for-that is, age, sex, severity of diseases, disability, and serum albumin concentration.

Gussekloo et al state that mental state may act as an important predictor of survival in elderly people. Although we did not find a significant association between mild cognitive impairment and mortality (relative risk $1.8(95 \%$ confidence interval 0.7 to 4.8$)$ ), our data are in line with their conclusions supporting the need to assess mental state to predict the survival of very elderly people.

Renzo Rozzini Chief

Medical Unit for the Acute Care of the Elderly, Poliambulanza Hospital, Brescia, Italy

Simone Franzoni Chief

Geriatric Evaluation and Rehabilitation Unit, Richiedei Hospital, Gussago, Brescia

\section{Giovanni B Frisoni Doctor}

Marco Trabucchi Professor

Geriatric Research Group, 25122 Brescia

1 Gussekloo J, Westendorp RGJ, Remarque EJ, Lagaay AM, Hereen TJ, Knook DL. Impact of mild cognitive mpairment on survival in very elderly people: cohor study. BMJ 1997;315:1053-4. (25 October.)

2 Greenfield S, Blanco DM, Elashoff RM. Development an testing of a new index of comorbidity. Clin Re 1987;35:346A

3 Katz S, Downs TD, Cash HR Grotz RC. Progress in development of the index of ADL. Gerontologist 1970;10(1): 20-30.

4 Brink TL, Yesavage JA, Lum O, Heersema PH, Adey M, Rose TL. Screening tests for geriatric depression. Clin Gerontol 1982;1:37-43.

5 Folstein MF, Folstein SE McHugh PR Mini-mental state: practical method for grading cognitive state of patients for the clinician. J Psychiatr Res 1975;12:189-98.

\section{Authors' reply}

EDITOR-The mini-mental state examination is widely used to screen for cognitive impairment in (very) elderly people. We emphasise that $40 \%$ of the participants of the Leiden 85-plus study had optimal scores of 28-30 points. ${ }^{1}$ As we described earlier, elderly subjects with test scores of 28-30 points tend to have equal scores over a period of three years. ${ }^{2}$ In contrast, subjects with borderline scores of 24-27 points tend to have lower scores over a similar period of time. In our paper we showed that subjects with borderline test scores have a higher risk of mortality.

Whether these subtle differences in scores on the mini-mental state examination are due to differences in cognition is debatable. However, test scores of 24-27 points and of 28-30 points undoubtedly distinguish different people. These findings are confirmed by the observations of Rozzini et al. Their data suggest that the increased risk of mortality in subjects with borderline tes scores is not due to comorbidity. The risk estimates were not materially different after adjustment for concurrent chronic diseases diagnosed in hospital. These observations strengthen the role of mental state as an

Crude and adjusted associations of score on mini-mental state examination with mortality after 12 months in 650 elderly patients

\begin{tabular}{cccc} 
Score & Proportion of deaths & Crude relative risk $\mathbf{( 9 5 \%} \mathbf{~ C I})^{*}$ & Adjusted relative risk (95\% $\mathbf{~ C l ) \dagger \ddagger ~}$ \\
\hline $28-30$ & $5 / 94$ & 1.0 & 1.0 \\
\hline $24-27$ & $18 / 194$ & $1.8(0.7$ to 4.9$)$ & $1.8(0.7$ to 4.8$)$ \\
\hline $19-23$ & $25 / 131$ & $3.8(1.5$ to 10.0$)$ & $2.6(1.0$ to 6.9$)$ \\
\hline $0-18$ & $65 / 231$ & $6.2(2.5$ to 15.4$)$ & 3.6 (1.4 to 9.2$)$ \\
\hline
\end{tabular}

${ }^{\star} P<0.0001$ in test for trend with decreasing score.

$\dagger$ Adjusted for age, sex, severity of disease (ischaemic or organic heart disease, heart disease of other origin, respiratory disease, kidney diseases, anaemia, and malignancy), serum albumin concentration, and disability.

$\ddagger \mathrm{P}=0.003$ in test for trend with decreasing score. important risk factor for mortality. Taken together, we can conclude that the minimental state examination is a valid instrument to differentiate subjects at higher risk at a cut off score of 27 points.

Forster et al doubt whether the minimental state examination has similar predictive properties when used by doctors in clinical practice instead of the two researchers in the Leiden 85-plus study. We are convinced that scores in the mini-mental state examination are reproducible when the instructions of the test are taken seriously. ${ }^{3}$ Indeed, the predictive value of a score for one subject has to be weighted differently from the predictive value of scores for a group of subjects, but this dilemma holds for every instrument used to screen for subjects at high risk. ${ }^{4}$

J Gussekloo General practitioner

E J Remarque Research fellow

A M Lagaay Senior registrar

D L Knook Professor

Section of Gerontology and Geriatrics, Departmen

of General Internal Medicine, University Hospital

Leiden, P-3-Q , PO Box 9600, 2300 RC Leiden,

Netherlands

R G J Westendorp Senior registrar

Clinical Epidemiology Leiden, University Hospital Leiden, Leiden

T J Heeren Professor

Department of Psychiatry, University of Utrecht, Utrecht, Netherlands

1 Heeren TJ, Lagaay AM, van Beek WCA, Rooijmans HGM, Hijmans W. Reference values for the mini-mental state examination (MMSE) in octo- and nonagenarians. $J$ Am Geriatr Soc 1990:38:1093-6.

2 Izaks GJ, Gussekloo J, Dermout KMT, Heeren TJ, Ligthart GJ. Three-year follow-up of mini-mental state examination score in community residents aged 85 and over. Psychol Med 1995;25:841-8.

3 Folstein MF, Folstein SE, McHugh PR. Mini-mental state: a practical method for grading the cognitive state of patients for the clinician. J Psychiatr Res 1975;12:189-98.

4 Wald NJ, Law M, Watt HC, Wu T, Bailey A, Johnson AM, et al. Apolipoproteins and ischemic heart disease: implications for screening. Lancet 1994:343:75-9.

\section{Medical students may not like statistics, but as doctors they will}

EDITOR-In his book review, Wessely finds Sinclair's analysis of medical education in Making Doctors depressing because Sinclair reports that medical students regard the psychiatrist as "the lowest form of medical life." Further, they do this because of the very things of which Wessely is rightly proud: psychiatrists' use of a questioning, multidisciplinary, evidence based, patient centred approach.

Wesseley was shocked to read that "statistics is above all the subject most disliked by students." This is no surprise to those of us given the task of teaching it to them. However, statistics teachers can console themselves with the thought that this dislike will not always be there, and that as these doctors progress through their careers they will find statistics of ever increasing relevance and importance. The BMJ shows this clearly in the research it publishes, in the large number of statistical articles it carries, and in its statistical refereeing. 
When I was a student, the attitude to my subject was: "Here's to pure mathematics, may it never be any use to anybody." The ultimate goal, now achieved, was the proof of Fermat's last theorem. I soon learnt that this would not take me far in the outside world and that being of use to people, and to doctors in particular, was far more rewarding. In the same way, Sinclair's medical students will learn that not all problems can be solved with a scalpel.

We continue to grow after leaving full time education. Given what Sinclair tells us, this is just as well.

J Martin Bland Professor of medical statistics Department of Public Health Sciences, St George's Hospital Medical School, London SW17 ORE

1 Wessely S. Medicine and books: Making doctors: an institutional apprenticeship. BMJ 1998;316:713. (28 February)

\section{Effect of moderate alcohol consumption on $\mathrm{Lp}(\mathrm{a})$ lipoprotein concentrations}

\section{Reduction is supported by other studies}

EDITOR-We agree with Paassilta et al that there may be a relation between moderate alcohol consumption and lower $\mathrm{Lp}(\mathrm{a})$ lipoprotein concentrations. ${ }^{1}$ The relation between alcohol consumption and cardiovascular mortality is $\mathrm{U}$ shaped, with the lowest mortality at an alcohol consumption of 2-4 units (16-32 g) a day. ${ }^{2}$ Several mechanisms contribute to this cardioprotective effect including beneficial increases in high density lipoprotein cholesterol ${ }^{3}$ and inhibition of platelet aggregation. ${ }^{4}$ However, other factors may be involved. $\mathrm{Lp}$ (a) lipoprotein is a recognised independent risk factor for the development of atherosclerosis and, as stated by Paassilta et al, little attention has been directed to the effects of alcohol on Lp(a) lipoprotein

In 1995 we reported a significant reduction in $\mathrm{Lp}$ (a) lipoprotein concentration in a prospective study of 20 healthy volunteers (men and women) given $21 \mathrm{~g}$ of alcohol daily for 10 days in the form of red wine (median (range) 186 (15-1420) mg/l $v 132$ (10-1210) mg/l, $\mathrm{P}<0.001) .{ }^{5}$ This reduction was not repeated when the same subjects were given white wine, raising the issue of potential differences between various alcoholic drinks. Interestingly, we found no changes in high density lipoprotein cholesterol concentrations.

We have conducted a larger unpublished crossover trial in 50 men comparing the effects of 3 units (24 g) of alcohol a day as red wine or vodka for 14 days on $\operatorname{Lp}(\mathrm{a})$ lipoprotein concentrations. Each period of alcohol consumption was preceded by two weeks' abstinence. Both drinks produced a $10-12 \%$ decrease in $\mathrm{Lp}(\mathrm{a})$ concentration (geometric mean $153 \mathrm{mg} / 100 \mathrm{ml} v$ $135 \mathrm{mg} / \mathrm{l}$ after vodka, $\mathrm{P}<0.001 ; 151 \mathrm{mg} / \mathrm{l} v$ $136 \mathrm{mg} / \mathrm{l}$ after red wine, $\mathrm{P}<0.01)$. These results suggest that moderate alcohol consumption results in changes in $\mathrm{Lp}(\mathrm{a})$ type of alcoholic drink consumed. In conclusion, we agree with Paassilta et al that lower $\mathrm{Lp}$ (a) concentrations may be one factor conferring lower mortality and cardiovascular benefit in social drinkers.

Peter C Sharpe Senior registrar in clinical biochemistry

Ian S Young Consultant in clinical biochemistry Department of Clinical Biochemistry, Queen University of Belfast and Royal Hospitals Trust, Belfast BT12 6BA

Alun E Evans Professor of epidemiology Division of Epidemiology, Queen's University of Belfast

1 Paassilta M, Kervinen K, Rantala AO, Savolainen MJ, Lilja $\mathrm{M}$, Reunanen A, et al. Social alcohol consumption and low Lp(a) lipoprotein concentrations in middle aged Finnish men: population based study. BMJ 1998;316:594-5.(21 men: pop

2 Kannel WB, Ellison RC. Alcohol and coronary heart disease-the evidence for a protective effect. Clin Chim Act disease-the evic

3 Paunio M, Heinonen OP, Virtamo J, Klag MJ, Manninen V, Albanes D, et al. HDL cholesterol and mortality in Finnish men with special reference to alcohol intake. Circulation 1994;90:2909-18.

4 Renaud S, De Lorgeril M. Wine, alcohol, platelets and the French paradox for coronary heart disease. Lancel 1992;339:1523-6.

5 Sharpe PC, McGrath LT, McClean E, Young IS, Archbold GPR. Effect of red wine consumption on lipoprotein (a) and other risk factors for atherosclerosis. $Q J$ Med $1995 ; 88: 101-8$

\section{No effect seen in Australian drinkers}

EDITOR-Paassilta et al suggest that a moderate intake of alcohol in Finnish men is associated with a roughly $50 \%$ reduction in median $\mathrm{Lp}$ (a) lipoprotein concentration. ${ }^{1}$ We have published relevant data from a large Australian cohort participating in an ongoing prospective study of cardiovascular disease (2805 subjects $\geqslant 60$ years, average age 70 years). ${ }^{2}{ }^{3}$

Current alcohol intake was assessed by personal interview and classified as nil, 10-70 g/week, 80-140 g/week, $150-280 \mathrm{~g}$ / week, and $>280 \mathrm{~g} /$ week (the last group in men only). The third and fourth groups correspond most closely with the middle and highest third of alcohol intake described by Paassilta et al. ${ }^{1} \mathrm{Lp}(\mathrm{a})$ lipoprotein concentration was assessed by a sandwich enzyme linked immunosorbentassay (ELISA) with polyclonal sheep antibody raised against purified human apo(a) (TintElize Lp(a) Biopool, Sweden). The table shows median (interquartile range) $\mathrm{Lp}(\mathrm{a})$ lipoprotein and mean high density lipoprotein cholesterol concentrations by sex and alcohol intake.

There was no significant relation between $L p(a)$ lipoprotein concentration and alcohol intake in either sex. We drew lipoprotein which are independent of the

similar conclusions when the data were examined in those below or above 70 years of age. The usual positive relation between alcohol intake and high density lipoprotein cholesterol was confirmed. Paassilta et al examined only 259 men aged 40-60 years. The median $\mathrm{Lp}(\mathrm{a})$ lipoprotein concentration in 37 teetotallers seemed high at 206 $\mathrm{mg} / \mathrm{l}$, and this may have been a spurious result. Surprisingly, they found no relation between alcohol intake and high density lipoprotein cholesterol concentration. Though we have reported that any alcohol intake in our cohort is associated with reduced coronary risk ${ }^{3}$ and raised $\mathrm{Lp}(\mathrm{a})$ lipoprotein concentration is associated with increased coronary risk, ${ }^{2}$ any link between alcohol intake and Lp(a) lipoprotein concentration seems unlikely.

Leon A Simons Associate professor of medicine Judith Simons Analyst-programmer

University of New South Wales, Lipid Research Department, St Vincent's Hospital, Darlinghurst, NSW 2010, Australia

1 Paassilta M, Kervinen K, Rantala AO, Savolainen MJ, Lilja $\mathrm{M}$, Reunanen A, et al. Social alcohol consumption and low $\mathrm{Lp}$ (a) lipoprotein concentrations in middle aged Finnish men: population based study. BMJ 1998;316:594-5 (21 February.)

2 Simons LA, Friedlander Y, McCallum J, Simons J. Risk factors for coronary heart disease in the prospective Dubbo study of Australian elderly. Atherosclerosis 1995;117:107-18.

3 Simons LA, McCallum J, Friedlander Y, Simons J. Alcohol intake and survival in the elderly: a 77 month follow-up on the Dubbo study. Aus NZ J Med 1996;26:662-70.

\section{Reduction is not found in women}

EDITOR-Paassilta et al showed a quantitative association between social alcohol consumption and low $\mathrm{Lp}$ (a) lipoprotein concentrations in middle aged men. ${ }^{1}$ As they indicated, we reported a negative qualitative association between drinking habits and $\mathrm{Lp}$ (a) lipoprotein concentrations in men.? We report here the results of a quantitative analysis of the association between alcohol intake and $\mathrm{Lp}$ (a) lipoprotein concentration in the Jichi Medical School cohort study. During 1992-5 we collected population based data in rural districts in Japan. The 9532 subjects (3658 men and 5874 women), which included all subjects in our previous report, were divided into five categories by drinking status; non-drinkers, (963 men), former drinkers (140 men), drinkers in the lowest third of alcohol intake $(<107 \mathrm{~g} /$ week; $711 \mathrm{men}$ ), drinkers in the middle third (107-224 g/week; $942 \mathrm{men}$ ), and drinkers in the highest third (>224 g/week; 902 men). Serum $\mathrm{Lp}(\mathrm{a})$ lipoprotein concentrations were measured with an enzyme linked

Median (interquartile range) Lp(a) lipoprotein and mean high density lipoprotein (HDL) cholesterol concentrations by sex and alcohol intake

\begin{tabular}{|c|c|c|c|c|c|c|}
\hline \multirow{2}{*}{$\begin{array}{l}\text { Alcohol } \\
\text { consumption } \\
\text { (g/day) }\end{array}$} & \multicolumn{3}{|c|}{ Men } & \multicolumn{3}{|c|}{ Women } \\
\hline & No & $\begin{array}{l}\text { Lp(a) lipoprotein } \\
\text { (mg/l) }\end{array}$ & $\begin{array}{l}\text { HDL cholesterol } \\
(\mathrm{mmol} / \mathrm{l})\end{array}$ & No & $\begin{array}{l}\text { Lp(a) lipoprotein } \\
\text { (mg/l) }\end{array}$ & $\begin{array}{l}\text { HDL cholesterol } \\
(\mathrm{mmol} / \mathrm{l})\end{array}$ \\
\hline 0 & 262 & $90(40-255)$ & 1.12 & 739 & $115(50-275)$ & 1.37 \\
\hline $10-70$ & 425 & $100(40-240)$ & 1.16 & 570 & $125(60-310)$ & 1.45 \\
\hline $80-140$ & 266 & $103(45-280)$ & 1.29 & 197 & $125(45-310)$ & 1.62 \\
\hline $150-280$ & 160 & $88(45-230)$ & 1.39 & 42 & $125(65-260)$ & 1.70 \\
\hline$>280$ & 97 & $85(35-205)$ & 1.42 & - & - & - \\
\hline
\end{tabular}


Mean atherosclerotic risk factors by alcohol consumption for men in the Jichi Medical School study, 1992-5

\begin{tabular}{|c|c|c|c|c|c|c|c|c|c|c|c|}
\hline & \multicolumn{2}{|c|}{ Non-drinker } & \multicolumn{2}{|c|}{ Former drinker } & \multicolumn{2}{|c|}{$<107 \mathrm{~g} /$ week } & \multicolumn{2}{|c|}{ 107-224 g/week } & \multicolumn{2}{|c|}{$>224$ g/week } & \multirow[b]{2}{*}{$P$ value } \\
\hline & No & Mean & No & Mean & No & Mean & No & Mean & No & Mean & \\
\hline Age (years) & 963 & 57.5 & 140 & 61.3 & 711 & 54.8 & 942 & 53.9 & 902 & 54.9 & $<0.0001$ \\
\hline Body mass index $\left(\mathrm{kg} / \mathrm{m}^{2}\right)$ & 958 & 22.9 & 138 & 23.1 & 703 & 23.1 & 941 & 22.9 & 898 & 22.9 & 0.74 \\
\hline Lp(a) lipoprotein $(\mathrm{mg} / \mathrm{l})^{\star}$ & 963 & 135 & 140 & 120 & 711 & 129 & 942 & 128 & 902 & 107 & $<0.0001$ \\
\hline Fibrinogen $(g / l)$ & 570 & 2.46 & 97 & 2.55 & 530 & 2.42 & 713 & 2.42 & 643 & 2.38 & $<0.05$ \\
\hline
\end{tabular}

*Geometric means were calculated for Lp(a).

$\dagger P$ values for variables except age were calculated after adjustment for age by analysis of covariance.

immunosorbent assay (ELISA) and Lp(a) lipoprotein and triglyceride concentrations were calculated as geometric means. We used SAS software for statistical analysis.

The groups were similar regarding body mass index and total cholesterol concentrations. The mean age of former drinkers was higher than that of men in the other groups (analysis of variance $\mathrm{P}<0.0001$ ). We therefore adjusted for age in all other analyses. Lp(a) lipoprotein concentration decreased with increased alcohol consumption in men except in former drinkers (table). Fibrinogen concentrations fell with increasing alcohol consumption $(\mathrm{P}<0.05)$.

For women the geometric mean $\mathrm{Lp}(\mathrm{a})$ concentrations were $148 \mathrm{mg} / \mathrm{l}$ in nondrinkers, $144 \mathrm{mg} / 1$ in former drinkers, $144 \mathrm{mg} / \mathrm{l}$ in lowest third, $136 \mathrm{mg} / \mathrm{l}$ in middle third, and $138 \mathrm{mg} / \mathrm{l}$ in highest third. There was no significant association between $\mathrm{Lp}(\mathrm{a})$ lipoprotein concentration and alcohol consumption $(\mathrm{P}=0.27)$. Fibrinogen concentrations decreased with increasing consumption $(\mathrm{P}<0.0001)$.

Our analysis shows a negative relation between alcohol consumption and and $\mathrm{Lp}$ (a) lipoprotein concentrations in men but not in women. These results support Paassilta et al's study and confirm our previous qualitative analysis.

Shizukiyo Ishikawa Researcher

Tadao Goto Researcher

Naoki Nago Visiting lecturer

Department of Community and Family Medicine, Jichi Medical School, Minamikawachi, Kawachi, Tochigi, Japan

1 Paassilta M, Kervinen K, Rantala AO, Savilainen MJ, Lilja $\mathrm{M}$, Reunanen A, et al. Social alcohol consumption and low Lp(a) lipoprotein concentrations in middle aged Finnish men: population based study. BMJ 1998:316:594-5. (21 February.)

2 Nago N, Kyaba K, Hiraoka J, Matsuo H, Goto T, Kario K, et al. Lipoprotein(a) levels in the Japanese population: influence of age and sex, and relation to atherosclerotic risk factors. Am J Epidemiol 1995;141:815-21.

\section{Information "Nuggets" are not easy to find quickly}

EDITOR-An essential ingredient in the practice of evidence based medicine is the evidence, but where can it be found? My recent experience using Medline and Embase suggests that these databases are not the place for a busy general practitioner to seek evidence with which to answer clinical questions. Only $40 \%-46 \%$ of a physician's clinical questions can be answered using Medline, ${ }^{12}$ and many of the citations retrieved in a Medline search are irrelevant. ${ }^{3}$ Evaluated databases such as the Cochrane database and Best Evidence are more helpful to me than the raw, undigested research that is available from Medline, but even they are not concise enough to use easily to answer a particular clinical question.

Slawson and Shaughnessy suggested that doctors are seeking "patient oriented evidence that matters (POEM)." ${ }^{*}$ When faced with a clinical question I would like information NUGGETS. I want information Now, Up to date, Grounded in Good Evidence, There (on my desk), and Specific to the problem. Where can I find a system that will deliver information NUGGETS?

Nimmi Naidoo General practitioner

Nuffield Health Centre, Witney, Oxfordshire OX8 7HQ

1 Osheroff JA, Bankowitz RA. Physicians' use of compute software in answering clinical questions. Bull Med Lib Assoc 1993;81:11-9.

2 Gorman PN, Ash J, Wykoff L. Can primary care physicians questions be answered using the medical journa literature? Bull Med Libr Assoc 1994;82:140-6.

3 Haynes RB, McKibbon A, Walker CJ, Ryan N, Fitzgerald D, Ramsden MF. Online access to Medline in clinical settings. Ann Int Med 1990;112:78-84.

4 Slawson DC, Shaughnessy AF. Obtaining useful information from expert based sources. BMJ 1997;314:947-9.

\section{Interventions to treat shoulder pain}

\section{Review was overly negative}

EDITOR-The systematic review by Green and colleagues of interventions for treating shoulder pain concluded that there is little evidence to support the use of any of the common interventions for the management of shoulder pain. ${ }^{1}$ This is a negative message that is likely to inhibit practitioners from treating patients with shoulder pain and to dissuade them from referring these patients to specialists. While we agree with the other conclusions of the study, we disagree with the negative message about treatment for several reasons.

Rheumatologists make decisions about the treatment of musculoskeletal disorders such as shoulder pain based on the duration of the condition, its severity, and a careful examination to define the exact site of the lesion. ${ }^{2}$ It is generally taught, for example, that the injection of corticosteroids will only work if done soon after the onset of any shoulder disorder and if the injection has been precisely localised to the anatomical site of the problem, such as a specific tendon or bursa within the rotator cuff. ${ }^{3}$ In the systematic review of the evidence great weight was given to the quality of the studies, but no weight was given to the quality of the clinical input to the studies, or to any of the three clinical criteria described above.

We would agree that the assessment of the value of treatments for shoulder pain is difficult because of the overall poor quality of published studies, the absence of agreed outcome measures, and a lack of uniformity of definitions; some recent rheumatological research has addressed the problem of definitions. ${ }^{4}$ However, the methods used to assess quality in this review are not transparent or validated, and it is unclear on what basis the authors chose to combine studies; this throws into question the validity of their conclusions.

Furthermore, if, as the authors of this and other reviews of interventions to treat shoulder pain contend, the methodological scores for most studies are low, surely it is erroneous to conclude that treatments do not work. The poor quality of the evidence discredits the negative conclusions as well as the positive ones.

Bela Szebenyi Consultant rheumatologist National Institute of Rheumatology and Physiotherapy, H-1525, Budapest 114, Hungary

Paul Dieppe Director

Medical Research Council Health Services Research Collaboration, University of Bristol, Bristol BS8 2PR

1 Green S, Buchbinder R, Glazier R, Forbes A. Systematic review of randomised controlled trials of interventions for
painful shoulder: selection criteria, outcome assessment, and efficacy. BMJ 1998;316:354-60. (31 January.)

2 Szebenyi B. Non-pharmacological approaches to pain management: can drugs be avoided? In: Pain in musculoskeletal diseases: new concepts for an age-old question. XIX ILAR congress of rheumatology, Singapore 1997. Hong Kong: Excerpta Medica, 1998.

3 Dalton S. The shoulder. In: Klippel J, Dieppe P, eds. Rheumatology. 2nd ed. London: Mosby, 1998

4 Pope DP, Croft PR, Pritchard CM, Silman AJ. Prevalence of shoulder pain in the community: the influence of case definition. Ann Rheum Dis 1997;56:308-12.

\section{Lack of concordance between} rheumatologists may render multicentre studies invalid

EDITOR-As Green et al point out the management of shoulder pain is bedevilled by imprecise diagnostic criteria. ${ }^{1}$ It is likely that many trials that examine the efficacy of treatment are flawed because treatment has been directed at the wrong part of the shoulder mechanism.

As there are only three joints and two main tendons in the shoulder it ought not be too difficult to agree a simple set of 
diagnoses with appropriate signs. But this is not enough. Our own study showed that three consultant rheumatologists who examined the same patients disagreed on the precise diagnosis in over $50 \%(14 / 26)$ of the cases, and when they examined a second group of patients together (so that they agreed on the clinical signs) they still disagreed in nearly $20 \%(4 / 18)$ of the cases. ${ }^{2}$

Such a lack of concordance among clinicians who are experienced in the management of shoulder problems will render any multicentre study invalid, and may leave any study by an individual clinician open to doubt or criticism.

Andrew Bamji Consultant rheumatologist Department of Rheumatology, Queen Mary's Hospital, Kent DA14 6LT

1 Green S, Buchbinder R, Glazier R, Forbes A. Systematic review of randomised controlled trials of interventions for painful shoulder: selection criteria, outcome assessment, and efficacy. BMJ 1998:316:354-60. (31 January.)

2 Bamii AN Erhardt CC Price TR Williams PL The painful shoulder: can colsultants agree? $B r \quad J$ Rheinato 1996;35:1172-4.

\section{Authors' reply}

EDITOR-Szebenyi and Dieppe have adopted an overly pessimistic reaction to our paper by misquoting our conclusions. The abstract and the further research section clearly state that "there is little evidence to either support or refute the efficacy of common interventions for shoulder pain."

The suggestion that careful clinical assessment will identify the problem is questionable. As Bamji points out, one of the important findings of our study (and his own), is a lack of concordance in the labelling and defining of shoulder disorders. This presents difficulties for those performing clinical trials as well as for clinicians who rely on the results to manage their patients. It is also of concern for those who use databases to make inferences about these conditions. ${ }^{1}$ The need for formal development and universal adoption of valid and reliable criteria for classifying shoulder disorders has been highlighted previously. ${ }^{2}$

Teaching students that the injection of corticosteroids will only work if done shortly after the onset of symptoms and if the injection has been precisely localised does not seem to be based on any evidence. One problem is the inability to precisely localise the injection. Previous studies have suggested that as many as $60 \%$ of shoulder injections thought to be intra-articular may not be. ${ }^{34}$

The methods we used to assess methodological quality have been well validated and are described in the reference cited in the review. ${ }^{5}$ Complete details will shortly be available from the Cochrane Library Musculoskeletal Group. The overall score of methodological quality was calculated based on an assessment of the study population (selection criteria, randomisation, comparable control group, and complete follow up), description of the intervention, measurement of the effect (blinding of patient and assessor, outcome measures), and data analysis (including complete presentation of results and consideration of sample size) The criteria used to combine the studies is specified in the methods section. Trials considered for pooling were those in which the same intervention was used in similar populations and in which the same outcome measure was used at similar lengths of follow up.

Further clinical trials are needed to determine optimal treatment strategies for shoulder pain. While such trials have the potential to be bedevilled by problems of diagnostic criteria, unlike Bamji we believe that careful consideration of selection criteria and outcome measures are not insurmountable challenges.

Rachelle Buchbinder Senior lecturer in clinical epidemiology

\section{Sally Green $P h D$ scholar}

Andrew Forbes Senior lecturer in biostatistics

Department of Epidemiology and Preventive

Medicine, Monash University, Melbourne 3186,

Australia

Richard Glazier Assistant professor

Family and Community Medicine, Preventive

Medicine and Biostatistics, University of Toronto,

Ontario, Canada

1 Buchbinder R, Goel V, Bombardier C. The lack of concordance between the ICD-9 classification of soft tissue cisor the of mill's experience. Am J Ind Medicin 1996:29:171-8

2 Buchbinder R, Goel V, Bombardier C. Classification systems of soft tissue disorders of the neck and upper limb: do they satisfy methodological guidelines? J Clin Epidemiol 1996;49:141-9.

3 Jones A, Regan M, Ledingham J, Pattrick M, Manhire A, Doherty M. Importance of placement of intra-articula steroid injections. BMJ 1993;307:1329-30.

4 Eustace J, Brophy D, Gibney R, Bresnihan B, Fitzgerald O. Comparison of the accuracy of steroid placement with clinical outcome in patients with shoulder symptoms. Arthritis Rheum 1995;38:S249.

5 Glazier R, Buchbinder R, Bell M. Critical appraisal of continuing medical education in the rheumatic diseases for primary care physians. Atthritis Rheum 1995;38-533-8.

\section{Suspension of consultant raises serious issues}

EDITOR-The recent news item ${ }^{1}$ and the subsequent letter and correction ${ }^{2}$ about the hearing of Dr James Taylor before the General Medical Council have not taken account of some serious issues raised by this case which will affect interventional physicians, cardiologists, and radiologists as well as obstetricians, surgeons, and others.

The accusation had been about consent, not of medical negligence. Negligence forms no part of the hearing. At issue was the extent to which consent is covered in the standard consent form used in NHS hospitals. After lengthy debate by counsel both for the GMC and Dr Taylor, the GMC's legal adviser omitted the strong legal challenge by defending counsel. He relied on his interpretation of two previous, distinctly different, cases reviewed by the Privy Council.

It was accepted that "consent" may not be required if the medical action was "necessary, in the child's best interest, and medically justified." However, the GMC panel ruled that "necessary" meant "immediately life-threatening." It came to this conclusion on the basis of a "Guide to Consent" published by the NHS in 1991, and of legal precedents, which concerned adult patients of unsound or immature mind. The unanimous expert evidence in the present case was that the procedure undertaken had been fully justified, a crucial point totally ignored in the GMC's decision.

In all its hearings the GMC panel acts as both jury and judge-the strictly legal part being in the hands of its legal adviser, who pronounces on legal issues and precedent. His opinion is not questioned by the panel and is not open to challenge. This adviser is part of the panel-that is, not an independent judge.

Decisions at these hearings as to fact should be proved "beyond reasonable doubt." Yet these proceedings were conducted in a manner that seemed to require the defendant to prove himself to be innocent. The finding of "guilty of serious professional conduct" seems to go against the legitimate and admitted doubt concerning the implications of the consent. If the GMC wished to clarify consent, it could do so by issuing firm regulations (which it has so far failed to do), rather than by penalising one doctor.

Siding with the parents on the issue of consent, the GMC may make it impossible for doctors caring for children to act "first and always" (as the motto of the Great Ormond Street children's hospital states) in the interest of the child, whenever an unexpected and urgent procedure ought to be performed.

As matters now stand, doctors may be prevented from acting in the patient's best interest when the unforeseen arises and requires immediate attention.

There is no appeal to the GMC's decision, other than to the Privy Council. Should there not be an appeals procedure within the GMC?

Gerald Graham Retired consultant clinical physiologist

Whaddon, Buckinghamshire MK17 0LT

Tony Robinson Retired general practitioner

5 Valley Forge Drive, Tonbridge, Kent TN10 4EU

1 Dyer, C, Consultant suspended for not getting consent for cardiac procedure. $B M J$ 1998;316:955. (28 March.)

2 Goodwin JF, Somerville W. Punishment of doctors must fit Goodwin JF, Somerville W. Punishment of doctors must fit
their crime [correction appears in $B M J$ 1998;316:1677] $B M J$ 1998;316:1248. (18 April.)

\section{Correction}

Punishment of doctors must fit their crime

An authors' error occurred in this letter by Goodwin and Somerville. At the hearing the parents, both in their evidence and through their counsel, accused Dr Taylor not only of having acted without consent but also of actually having proceeded against their (allegedly previously expressed) wish. This part of their action, however, failed (contrary to the statement made in Goodwin and Somerville's letter). 